\title{
Next-Generation Sequencing Reveals a Novel Emaravirus in Diseased Maple Trees From a German Urban Forest
}

OPEN ACCESS

Edited by:

Ahmed Hadidi,

Agricultural Research Service,

United States Department

of Agriculture, United States

Reviewed by:

Beatriz Navarro,

Istituto per la Protezione Sostenibile delle Piante, Italy

Satyanarayana Tatineni, Agricultural Research Service,

United States Department

of Agriculture, United States

*Correspondence:

Artemis Rumbou

artemis.rumbou@agrar.hu-berlin.de

Specialty section:

This article was submitted to

Virology,

a section of the journa

Frontiers in Microbiology

Received: 25 October 2020

Accepted: 09 December 2020

Published: 08 January 2021

Citation:

Rumbou A, Candresse T, von Bargen S and Büttner C (2021) Next-Generation Sequencing Reveals a Novel Emaravirus in Diseased Maple

Trees From a German Urban Forest. Front. Microbiol. 11:621179.

doi: 10.3389/fmicb.2020.621179

\author{
Artemis Rumbou ${ }^{1 *}$, Thierry Candresse ${ }^{2}$, Susanne von Bargen ${ }^{1}$ and Carmen Büttner ${ }^{1}$ \\ ${ }^{1}$ Faculty of Life Sciences, Albrecht Daniel Thaer-Institute of Agricultural and Horticultural Sciences, Humboldt-Universität zu \\ Berlin, Berlin, Germany, ${ }^{2}$ UMR 1332 Biologie du Fruit et Pathologie, INRAE, University of Bordeaux, UMR BFP, \\ Villenave-d'Ornon, France
}

While the focus of plant virology has been mainly on horticultural and field crops as well as fruit trees, little information is available on viruses that infect forest trees. Utilization of next-generation sequencing (NGS) methodologies has revealed a significant number of viruses in forest trees and urban parks. In the present study, the full-length genome of a novel Emaravirus has been identified and characterized from sycamore maple (Acer pseudoplatanus) - a tree species of significant importance in urban and forest areas - showing leaf mottle symptoms. RNA-Seq was performed on the Illumina HiSeq2500 system using RNA preparations from a symptomatic and a symptomless maple tree. The sequence assembly and analysis revealed the presence of six genomic RNA segments in the symptomatic sample (RNA1: 7,074 nt-long encoding the viral replicase; RNA2: 2,289 nt-long encoding the glycoprotein precursor; RNA3: 1,525 ntlong encoding the nucleocapsid protein; RNA4: 1,533 nt-long encoding the putative movement protein; RNA5: 1,825 nt-long encoding a hypothetical protein P5; RNA6: 1,179 nt-long encoding a hypothetical protein P6). Two independent NGS sequencing runs from the same symptomatic maple tree detected the same genome segments. For one of these sequencing runs the cDNA library was prepared using a primer targeting the conserved genome terminal region, known to be shared between emaraviruses genome segments. We suggest, therefore, that the six identified genome segments represent the complete genome of a novel emaravirus from maple, which we tentatively name maple mottle-associated virus (MaMaV). Phylogenetic and sequence homology analyses place this virus on the distinct "subgroup a" clade within the Emaravirus genus along with - among others - rose rosette virus, Actinidia emaravirus 2, and fig mosaic virus. Validation RT-PCR assays performed on symptomatic and non-symptomatic trees suggest that MaMaV may be the symptom-inducing virus in the diseased trees. To our knowledge, this is the first time an Emaravirus is described from maple and is fully genetically characterized. With the discovery of MaMaV, the genus Emaravirus comprising negative-sense single-stranded viruses with very divergent genomes - that were until recently overlooked - has substantially increased counting 22 established and putative members.

Keywords: emaravirus, maple mottle-associated virus, maple virome, RNA-Seq, forest disease 


\section{INTRODUCTION}

Viruses of forest trees have been, until recently, only slightly characterized due to two main reasons; (a) biased sampling based on a restricted focus on agricultural crops and fruit trees viruses (Büttner et al., 2013) and (b) a general bias against the identification of the most divergent genomes (Zhang et al., 2018). Due to the utilization of next generation sequencing (NGS), however, forest virology has gained a significant momentum in identifying viruses infecting forest trees. Recently, a birch virome was unraveled revealing a complex of novel and known viruses (Rumbou et al., 2020), while a novel badnavirus associated with the birch leaf-roll disease was identified and genetically characterized (Rumbou et al., 2018). In mosaicdiseased Eurasian aspen (Populus tremula) a novel emaravirus has been identified (von Bargen et al., 2020a). European mountain ash ringspot-associated virus has been detected in new hosts like Karpatiosorbus $\times$ hybrida in Finland (von Bargen et al., 2020b), Sorbus intermedia (von Bargen et al., 2019), and Amelanchier spp. (von Bargen et al., 2018). It is apparent, that the application of NGS tools has substantially increased the rate of virus discovery in forest and urban green ecosystems.

Viral diseases of different maple species (Acer spp.) have been reported by plant virologists since long (Cooper, 1979). Atanasoff (1935) was probably the first to describe a "yellow mottle-mosaic" symptom in Acer negundo and A. pseudoplatanus in Japan and Europe, possibly related to virus presence. Brierley (1944) observed chlorotic or ring mottle in Acer saccharum in North America, and a similar symptom was reported by Ploiaie and Macovei (1968) in Romania. Szirmai (1972) described a "mosaic mottling with chlorotic - tending to yellow ochre spots" in A. negundo and A. pseudoplatanus in Hungary, while Cooper (1979) confirmed this symptomatology in maples in the United Kingdom. At the same time, mechanical transmission of the so-called "maple leaf perforation virus" from naturally infected maples to beans (Phaseolus vulgaris) was described by Subikova (1973), but without visualizing virus particles by electron microscopy (EM).

The graft-transmissibility of an agent causing leaf mottle in maples was earlier reported (Führling and Büttner, 1998), while rod-shaped virus particles approx. $300 \mathrm{~nm}$-long and genomic material from tobamoviruses were observed by EM in symptomatic leaves. Rod-shaped virus particles were also detected in young A. saccharum seedlings with chlorotic spots and mottle symptoms (Lana et al., 1980), which were attributed to tobacco mosaic virus based on their serological and biological properties. Isometric particles of $26-30 \mathrm{~nm}$ diameter were detected in maple trees from Turkish urban areas (A. negundo, A. pseudoplatanus, Acer campestre) exhibiting mottling, mosaic, leaf deformation and lateral shoot formation (Erdiller, 1986). These particles were attributed to arabis mosaic virus, cucumber mosaic virus and soybean mosaic virus. However, to date, Acer sp. has never been unambiguously described as a host for any wellcharacterized viral agent and data of the Virus-Host database also confirm that (Mihara et al., 2016).

Maples are abundantly found in European forests and urban parks, with the most common species A. pseudoplatanus (sycamore) and Acer platanoides (Norway maple) representing a natural component of birch (Betula sp.) and fir (Abies sp.) forests (Gibbs and Chen, 2009). Several Acer species provide valuable timber and are the main sources of maple sugar and maple syrup (Binggeli, 1993). Damages on the trees have been regularly attributed to fungi with most harmful being Verticillium wilt, sooty bark disease caused by Cryptostroma species (Wulf and Kehr, 2009) as well as Eutypella parasitica causing trunk infections (Brglez et al., 2020). Phytoplasma-associated witchesbroom disease has been reported in A. negundo (Kaminska and Suwa, 2006) as well as in Japanese maple, Acer palmatum (Li et al., 2012). Maple trees exhibiting virus-like symptoms were regularly observed in forests around Berlin as well as in other regions of Germany during the last 40 years (Bandte et al., 2008). However, viral agent(s) affecting maples have not been adequately characterized by conventional methods. Considering the ecological and economical importance of maples, we aimed to fill in the gap in maple's pathology by employing an RNASeq methodology to identify viruses possibly affecting maple trees. As a result, the genome of a novel viral agent is fully identified and characterized, while its association with the observed symptomatology is strongly suggested.

\section{MATERIALS AND METHODS}

\section{Plant Materials}

In 2014, leaf samples exhibiting virus-like symptoms, including mottle and leaf deformation (Figure 1), were collected from an A. pseudoplatanus tree in the Berlin-Grunewald urban forest [Acer+ (2014): symptomatic tree], where such symptoms have been monitored for at least two decades. Randomly selected leaf parts were pooled together and used for RNA extraction. A similar pool of leaves was obtained from a symptomless seedling [Acer- (2014): non-symptomatic tree]. In 2015, the same symptomatic tree was re-sampled and RNA was extracted from pooled leaves exhibiting symptoms [Acer+ (2015)].

For the investigation of the virus presence in the urban BerlinGrunewald forest, leaves were collected from symptomatic and non-symptomatic maples in order to be used for RNA isolation and RT-PCR diagnostic assays. In total, 26 sycamore maple trees exhibiting symptoms similar to those of the Acer+ (2014) tree as well as six trees without symptoms were tested in 2015, 2016 or 2019 (Supplementary Table 1).

\section{Next Generation Sequencing and Sequence Assembly}

Total RNAs were isolated from $100 \mathrm{mg}$ leaf tissue using the InviTrap Spin Plant RNA Mini Kit (STRATEC Molecular, Germany), followed by removal of remaining DNA with rDNase according to the supplier protocol (Macherey-Nagel, Germany) and RNA purification using NucleoSpin RNA Cleanup (Macherey-Nagel, Germany). Ribosomal RNA depletion was performed using the RiboMinus Plant Kit for RNA-Seq (Invitrogen). One to two micrograms of RiboMinus RNA of each sample were used for cDNA synthesis with the Maxima $\mathrm{H}$ Minus double-stranded cDNA synthesis Kit (Thermo Scientific) 


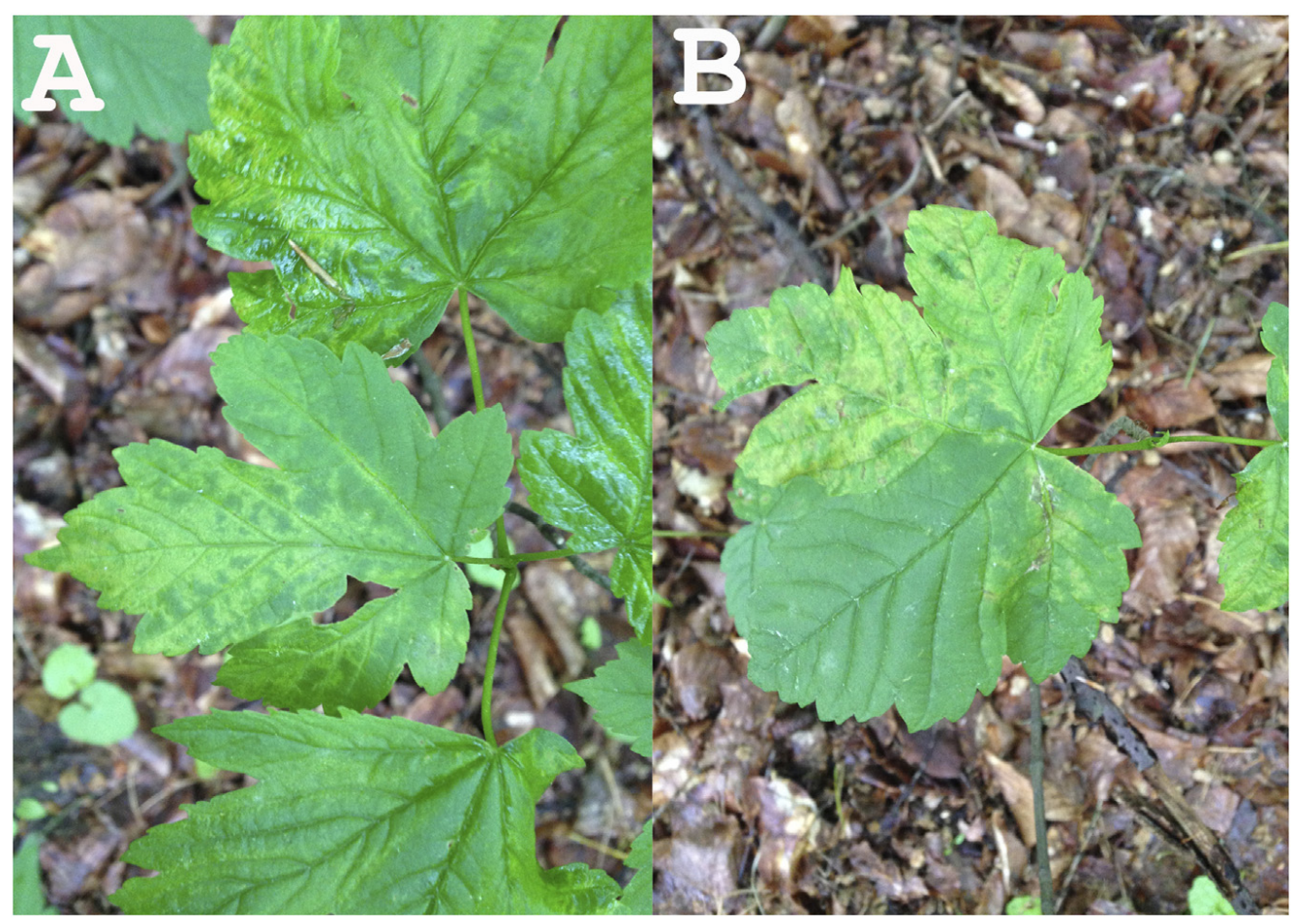

FIGURE 1 | Leaf symptoms of the tested sycamore tree subjected to NGS (A: leaf mottle; B: leaf mottle and deformation).

primed with random hexamers for samples Acer+ (2014) and Acer- (2014). For sample Acer+ (2015), the precipitated RNA was reverse transcribed into cDNA using the generic terminal primer PDAP213 (Di Bello and Tzanetakis, 2013).

Two micrograms purified double-stranded cDNA from each sample were sent to BaseClear (Netherlands) for RNA-Seq analysis on the Illumina HiSeq2500 system. FASTQ sequence files were generated using the Illumina Casava pipeline version 1.8.3. Initial quality assessment was based on data passing the Illumina Chastity filtering. Subsequently, reads containing adapters and/or PhiX control were removed using an in-house filtering protocol. The second quality assessment was based on the remaining reads using the FASTQC quality control tool version 0.10.0. NGS data processing and analysis were carried out either using CLC Genomics Workbench version 7.0.4. or the VirAnnot pipeline (Lefebvre et al., 2019). The quality of the FASTQ sequences was enhanced by trimming off low quality bases using the "Trim sequences" option of the CLC Genomics Workbench version 7.0.4. The quality-filtered reads were de novo assembled into contig sequences using CLC Genomics Workbench. Contigs annotation was carried out using BLASTn against the NCBI-GenBank databases. When needed, virusrelated contigs were manually assembled into larger scaffolds and scaffolds polished by re-mapping of reads on the scaffolds using CLC Genomics Workbench.

\section{Taxonomic Analysis of the Metagenome}

The taxonomic content of the obtained datasets, as provided by the BLAST annotations, was visualized using MEGAN (Huson et al., 2016), in which the BLAST results were parsed to assign the best hits to appropriate taxa in the NCBI taxonomy. As a result, the taxonomical content ("species profile") of the sample from which the reads were collected was estimated, with a particular focus on viral species.

\section{Validation of the Presence of Novel Virus in Maples}

Samples from 32 symptomatic and non-symptomatic maple trees were collected from two different locations in BerlinGrunewald and from grafted scions of that origin propagated in the experimental garden of Humboldt University of Berlin since 2017 (Supplementary Table 1). Symptomatic trees exhibited most often mottle, or mottle in combination with a mixture of other symptoms like flecking, chlorotic ringspots, vein banding, chlorotic line pattern, mosaic and/or leaf deformation. Pooled samples of $100 \mathrm{mg}$ leaf tissue from three to five leaves from different twigs of each tree were used. Total RNAs were isolated according to Boom et al. (1990).

To confirm the presence of the identified segments in the samples, specific RT-PCR assays were performed using segmentspecific primer pairs (Table 1). The first-strand cDNAs were synthesized from $1 \mu \mathrm{g}$ of total RNA in a $20 \mu \mathrm{l}$ reaction volume of 1x RT buffer (Thermo Scientific) containing $1 \mu \mathrm{M}$ dNTPs mix, $100 \mathrm{U}$ RevertAid Premium reverse transcriptase (Thermo Scientific), 20 U RiboLock RNase inhibitor (Thermo Scientific), and $100 \mathrm{pmol}$ of random hexamer-oligonucleotides 
TABLE 1 | Features of primers used for the specific RT-PCR detection of MaMaV.

\begin{tabular}{llc}
\hline Primer name & Primer sequence $\left(\mathbf{5}^{\prime} \mathbf{-} \mathbf{3}^{\prime} \mathbf{)}\right.$ & Product length $(\mathbf{b p})$ \\
\hline RNA1aF & AACCAATGCTGTCACTTAAGC & 346 \\
RNA1aR & GATATAACTACCATCTAACATCC & \\
RNA1bF & GGATGTAGATGGTAGTTATATC & 290 \\
RNA1bR & CCACTTATAGTATTGCTCACC & \\
RNA2F & GCAAGATITGATGTGGCTGG & 149 \\
RNA2R & AACCATCATGGCCATCACAAC & \\
RNA3F & TGTGCTATAATGGCAGCTGG & 289 \\
RNA3R & CATCAGTCATGCTATCTGGTATG & \\
RNA4F & TTGGACACCAACATCTACAAG & 470 \\
RNA4R & GCAATTCCTCCTCTCATTGT & \\
RNA5F & GAACTATGTCTTACCAACACTG & 221 \\
RNA5R & CTAATTCCCTAAGTTGATAGTAAC & \\
RNA6F & CAGATAACATATTCTCTTCTGG & 300 \\
RNA6R & AAGCGAGATATATGCTATGGCT & \\
\hline
\end{tabular}

(Biolegio). Subsequent PCR amplifications were conducted in a $50 \mu \mathrm{l}$ volume of $1 \mathrm{x}$ DreamTaq Buffer (Thermo Scientific) containing $0.2 \mu \mathrm{M}$ dNTP mix, $0.25 \mathrm{U}$ of DreamTaq DNA polymerase and $1 \mu \mathrm{M}$ of each forward and reverse primer. The thermal cycles were as follows: $2 \mathrm{~min}$ at $94^{\circ} \mathrm{C}$ followed by 35 cycles at $94^{\circ} \mathrm{C}$ for $30 \mathrm{~s}, 55^{\circ} \mathrm{C}$ for $30 \mathrm{~s}, 72^{\circ} \mathrm{C}$ for $30 \mathrm{~s}$, with a final extension step of $72^{\circ} \mathrm{C}$ for $5 \mathrm{~min}$. The product lengths amplified for the different RNA segments are shown in Table 1.

\section{Sequence Analysis and Phylogenetic Comparison of Novel Sequences}

Multiple nucleotide or amino acid sequence alignments as well as pairwise sequence identity calculations were performed using AliView version 1.17.1 (Larsson, 2015). ORF finder at $\mathrm{NCBI}^{1}$ was used to identify open reading frames (ORFs) on assembled genome segments and identify the encoded proteins. All ORFs with 300 or more nucleotides (nt) were considered. For the phylogenetic comparisons of complete coding regions, the 21 established and tentative emaravirus species identified to date and represented in GenBank were used. Maximum likelihood (ML) trees were constructed with MEGA6 (Tamura et al., 2013) applying the Jones-Taylor-Thornton (JTT) substitution model for amino acids. Robustness of nodes of the phylogenetic tree was assessed from 1,000 bootstrap replications and values $>70 \%$ were displayed for trees' internal nodes.

To perform preliminary genetic divergence analysis, 40 RTPCR products from 10 tested samples were directly submitted for Sanger sequencing (Macrogen) without previous cloning. They were amplified from three RNA segments; RNA1, RNA3, and RNA4. For RNA1, RT-PCR products were amplified in two different genome regions; the primer-pair RNA1aF/R generated PCR products of $311 \mathrm{nt}$ length (nt positions 3,006 - 2,756), while the primer pair RNA1bF/R generated 274 nt-long RTPCR products located at nt positions 3,317 - 3,042. Sequences of RT-PCR products for the RNA3 segment were 274 nt-long

${ }^{1}$ https://www.ncbi.nlm.nih.gov/orffinder/ (nt positions 734 - 468), while in the RNA4 segment RTPCR products of $431 \mathrm{nt}$ length were amplified (nt positions 835 - 405). Evolutionary analyses were conducted in MEGA6 (Tamura et al., 2013). Genetic distance between sequences was assessed applying the Maximum Composite Likelihood model (Tamura et al., 2004), where the number of base substitutions per site between sequences was calculated.

\section{RESULTS}

\section{Quality Analysis of FASTQ Sequence Reads, de novo Assembly and Taxonomic Analysis of the Metagenome}

RNA-Seq was performed in 2014 using RNA preparations from a symptomatic and a symptomless maple tree. 124 and $14 \mathrm{MB}$ data/sample with average quality of approx. 35 Phred were generated for Acer+ (2014) and Acer- (2014), respectively [620,460 FASTQ reads for Acer+ (2014); 69,353 FASTQ reads for Acer- (2014)] (Table 2). For the sample Acer+ (2014) the de novo assembly of quality-filtered pairedend reads resulted in 532 assembled contigs. Analysis identified 14 contigs exhibiting significant nt identities to RNA sequences of several emaraviruses as assessed by BLASTn (seven contigs with identities to emaravirus-RNA1 assembling a 6,005 bplong scaffold with missing genome parts within the sequence and at the ends; three contigs with identities to emaravirusRNA2 assembling a 1,761 bp-long scaffold; one contig 1,085 bplong with identities to emaravirus-RNA3; one 1,256 bp-long contig with identities to emaravirus-RNA4; one 1,277 bp-long contig with identities to RNA5 segment of some emaravirus species; one 928 bp-long contig with identities to RNA6 segment of some emaravirus species). All assembled contigs/scaffolds were missing sequences at the $3^{\prime}$ and $5^{\prime}$ ends. In the negative control sample Acer- (2014) none of the 30 contigs assembled showed any significant identities to emaraviruses or any other plant viruses. No other contigs from the Acer+ (2014) sample were identified as viral besides the 14 ones showing affinities with emaraviruses.

The contigs resulting from the de novo assembly of the reads for each sample were used for the MEGAN analysis. For the symptomatic sample Acer+ (2014), out of the 532 contigs assembled, 474 belong to Eucaryota, most of them to clade Euphylophyta (Phylum: Streptophyta; Kingdom: Viridiplantae) where Acer spp. is classified - and three belong to Bacteria. The 11 viral contigs identified by MEGAN are attributed to the Fimoviridae family and ten are attributed to pigeon pea sterility mosaic virus (Emaravirus, Fimoviridae). In the case of the non-symptomatic sample Acer- (2014), none of the 30 assembled contigs is attributed to a viral species. The taxonomic analysis performed by MEGAN show a high degree of consistency with the results delivered by BLASTn annotation and clearly suggest the presence of an emaravirus in the tested samples.

To confirm the RNA-Seq results from the Acer+ (2014) sample and to complete the missing parts of the detected genome 
TABLE 2 | Quality statistics of FASTQ sequence reads and de novo statistics for the three maple samples.

\begin{tabular}{|c|c|c|c|c|c|c|c|}
\hline \multirow[t]{2}{*}{ Plant } & \multirow{2}{*}{$\begin{array}{c}\text { FastQ } \\
\text { sequence reads }\end{array}$} & \multirow{2}{*}{$\begin{array}{l}\text { Sample Yield } \\
\text { (in MB) }\end{array}$} & \multicolumn{5}{|c|}{ De novo assembly } \\
\hline & & & $\begin{array}{l}\text { Total } \\
\text { reads }\end{array}$ & $\begin{array}{l}\text { Matched } \\
\text { reads }\end{array}$ & $\begin{array}{c}\text { Total } \\
\text { contigs }\end{array}$ & $\begin{array}{l}\text { Average contig } \\
\text { length (bp) }\end{array}$ & $\begin{array}{c}\text { Emara-specific } \\
\text { contigs }\end{array}$ \\
\hline Acer+ (2014) & 620,460 & 124 & $1,116,554$ & 924,998 & 532 & 677 & 14 \\
\hline Acer- (2014) & 69,353 & 14 & 123,424 & 115,795 & 30 & 984 & 0 \\
\hline Acer+ (2015) & 850,283 & 198 & $1,700,566$ & $1,496,745$ & 2,206 & 646 & 8 \\
\hline
\end{tabular}

segments, the whole NGS process was repeated in 2015 with leaves from the same tree. A ds-cDNA library was generated using the emara-specific terminal primer PDAP213, aiming to detect the missing genome ends. The RNA-Seq analysis provided a higher amount of sequence data (198 MB), delivering 850,283 FASTQ sequence reads (av. quality score: $\sim 35$ Phred) (Table 2). The de novo assembly resulted in a total of 2,206 contigs with an average length of $646 \mathrm{bp}$. BLASTn analysis identified eight long contigs exhibiting significant identities to emaraviruses (three with identities to emaravirus-RNA1, assembling a 6,907 bplong scaffold missing the $5^{\prime}$ end; one 2,289 bp-long contig with identities to emaravirus-RNA2; one 965 bp-long contig with identities to emaravirus-RNA3; one short 235 bp-long contig with identities to emaravirus-RNA4, one 1,851 bp-long contig with identities to RNA5 segment of some emaraviruses, and one $1,100 \mathrm{bp}$-long contig with identities to RNA6 segment of some emaravirus). The new contigs showed 100\% nucleotide identity with the ones generated from the same tree in 2014. As such, they were assembled together with the 2014 contigs, providing the full-length sequence of the various RNA segments. Finally, a polishing step was performed to ensure genome completion and the absence of errors and to confirm genome ends. As a result, complete sequence of six genomic RNA segments were obtained (RNA1: 7,074 nt; RNA2: 2,289 nt; RNA3: 1,525 nt; RNA4: 1,533 nt, RNA5: 1,825 nt; RNA6: 1,179 nt) (Figure 2). The full-length genomic sequences of the maple emaravirus RNA segments are deposited in GenBank under accession numbers MT879190-MT879195.

\section{Genome Structure and Encoded Proteins}

To identify ORFs on assembled genome segments, ORF Finder from NCBI was employed and identified six ORFs, one corresponding to each RNA segment. BLASTp annotation of the amino acid (aa) sequences derived from the assembled scaffolds from the symptomatic maple tree revealed high BLAST scores with RNA segments from viruses of the genus Emaravirus (Fimoviridae, Bunyavirales) (Table 3).

ORF1 predicted on RNA1 is 2,305 aa-long and the encoded protein shows in BLASTp analysis significant aa identity of 32$75 \%$ with the viral replicase of 21 known emaraviruses (ORF1: nt positions $6,966-49)$. The putative RNA polymerase exhibits highest aa identity with that of rose rosette virus (Accession number: QHZ99251.1; 74.4\% aa identity) (Figure 3).

ORF2 encoded on RNA2 is predicted to encode a protein of 646 aa (nt positions 1,996 - 56). In BLASTp comparisons the encoded protein shows $26-57 \%$ aa identity with 21 other

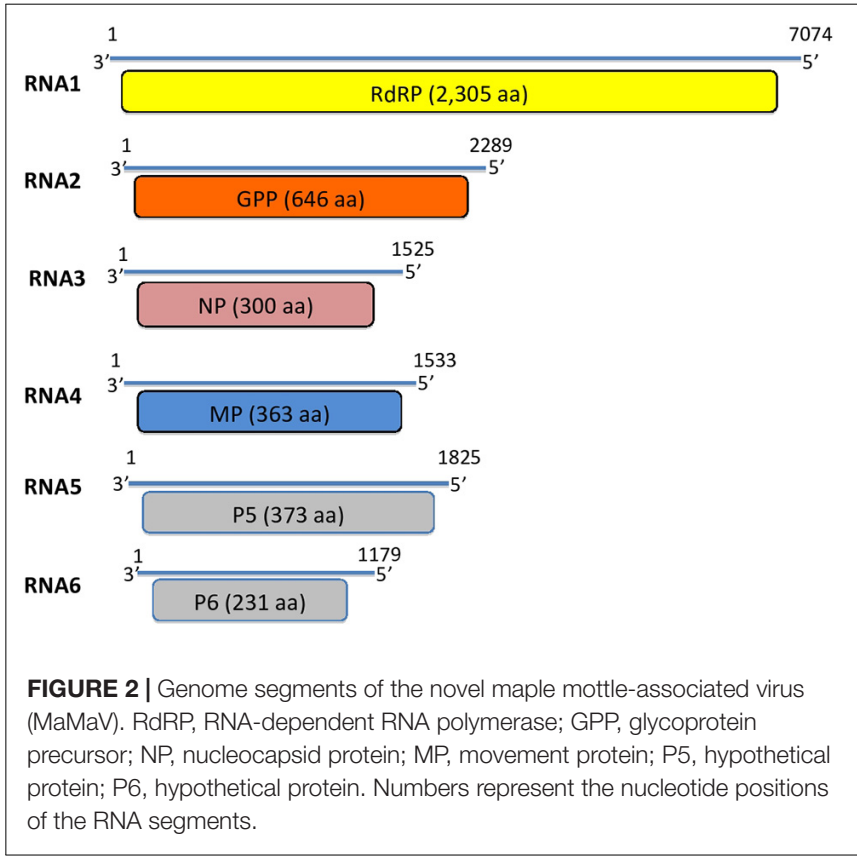

emaraviruses. The highest aa identity is with the glycoprotein precursor (GPP) of rose rosette virus (Accession number: QID76023.1; aa identity: 56.7\%).

ORF3 encoded on RNA3 is predicted to encode a protein of 300 aa (nt positions 104 - 1,006) with highest BLASTp aa identity with the nucleocapsid proteins (NP) of the 21 known emaraviruses (24-56\%). The ORF3-encoded protein shows highest aa identity with the NP protein of Actinidia emaravirus 2 (Accession number: QEE82888.1; aa identity: 55.6\%). In Table 3 the recently identified NP protein from pea-associated virus (Y.Z.A Gaafar and Ziebell, 2019, H; GenBank: QJX15716.1.) is also included, because ORF3 shows relatively high identity with it $(50.5 \%)$. There are, however, no other proteins identified from this tentative emaravirus.

ORF4 encoded on RNA4 is predicted to encode a protein of 363 aa (nt positions 1,179 - 88) which shows very variable BLASTp aa identity levels with the movement proteins identified from 20 emaraviruses (19-65\%). It exhibits highest aa sequence identity with the movement protein of fig mosaic virus (Accession number: BAM13817.1; aa identity: 65.2\%).

The fifth predicted ORF is encoded on RNA5 and is predicted to encode a protein of 373 aa (nt positions 1,526 - 93). The hypothetical protein encoded by RNA5 shows sequence 


\begin{tabular}{|c|c|c|c|c|c|c|c|}
\hline & & RdRP & GPP & NP & MP & P5 & P6 \\
\hline \multirow[t]{2}{*}{1} & Rose rosette virus & $74.40 \%$ & $56.65 \%$ & $51.77 \%$ & $64.84 \%$ & $44.81 \%$ & $42.04 \%$ \\
\hline & & QHZ99251.1 & QID76023.1 & QIB97971.1 & QIB98058.1 & QIB98219.1 & QJR96770.1 \\
\hline \multirow[t]{2}{*}{2} & Aspen mosaic-associated virus & $70.23 \%$ & $53.11 \%$ & $51.04 \%$ & $57.73 \%$ & - & $40.39 \%$ \\
\hline & & CAA0079389.1 & CAA0079597.1 & CAA0079646.1 & CAA0079685.1 & & CAA0079719.1 \\
\hline \multirow[t]{2}{*}{3} & Actinidia emaravirus 2 & $69.66 \%$ & $47.78 \%$ & $55.63 \%$ & $63.31 \%$ & $43.41 \%$ & $44.16 \%$ \\
\hline & & QEE82886.1 & QEE82887.1 & QEE82888.1 & QEE82889.1 & QEE82890.1 & QEE82891.1 \\
\hline \multirow[t]{2}{*}{4} & Pistacia emaravirus & $69.16 \%$ & $52.07 \%$ & $51.60 \%$ & $62.33 \%$ & $40.46 \%$ & $32.43 \%$ \\
\hline & & QAR18002.1 & QAR18003.1 & QAR18004.1 & QAR18005.1 & QAR18006.1 & QAR18008.1 \\
\hline \multirow[t]{2}{*}{5} & Fig mosaic emaravirus & $68.67 \%$ & $52.15 \%$ & $54.04 \%$ & $65.19 \%$ & $33.98 \%$ & $41.71 \%$ \\
\hline & & QBH72675.1 & QBK46595.1 & BAM13809.1 & BAM13817.1 & YP_009237273.1 & BAM13854.1 \\
\hline \multirow[t]{2}{*}{6} & Pigeon pea sterility mosaic emaravirus 1 & $53.58 \%$ & $46.56 \%$ & $40.29 \%$ & $62.64 \%$ & $42.92 \%$ & $37.70 \%$ \\
\hline & & ANQ90714.1 & QBA83603.1 & CDX09880.1 & ANQ90777.1 & CUR49054.1 & ANQ90719.1 \\
\hline \multirow[t]{2}{*}{7} & Pigeon pea sterility mosaic emaravirus 2 & $68.14 \%$ & $51.32 \%$ & $53.29 \%$ & $64.00 \%$ & $43.89 \%$ & $37.70 \%$ \\
\hline & & QBA83607.1 & YP_009268865.1 & ALU34071.1 & ANQ90759.1 & QBA83611.1 & ANQ90763.1 \\
\hline \multirow[t]{2}{*}{8} & Blackberry leaf mottle-associated virus & $66.09 \%$ & $52.22 \%$ & $50.17 \%$ & $56.32 \%$ & - & $35.57 \%$ \\
\hline & & AQX45473.1 & AQX45474.1 & AQX45475.1 & QBM15152.1 & & $A Q \times 45477.1$ \\
\hline \multirow[t]{2}{*}{9} & European mountain ash ringspot-associated emaravirus & $48.70 \%$ & $40.67 \%$ & $36.69 \%$ & $35.24 \%$ & - & - \\
\hline & & VFU05375.1 & YP_003104765.1 & SPN63240.1 & VFU05382.1 & & \\
\hline \multirow[t]{2}{*}{10} & Actinidia chlorotic ringspot-associated virus & $47.82 \%$ & $41.53 \%$ & $38.43 \%$ & $33.70 \%$ & - & - \\
\hline & & YP_009507925.1 & YP_009507926.1 & YP_009507928.1 & YP_009507927.1 & & \\
\hline \multirow[t]{2}{*}{11} & Lilac chlorotic ringspot-associated virus & 48.92\% QIN85945.1 & $42.61 \%$ & $40.69 \%$ & $36.56 \%$ & - & - \\
\hline & & & QIN85946.1 & QIN85947.1 & QIN85948.1 & & \\
\hline \multirow[t]{2}{*}{12} & Redbud yellow ringspot-associated emaravirus & $47.27 \%$ & $40.96 \%$ & $37.91 \%$ & $35.85 \%$ & - & - \\
\hline & & YP_009508083.1 & YP_009508087.1 & YP_009508085.1 & YP_009508084.1 & & \\
\hline \multirow[t]{2}{*}{13} & Ti ringspot-associated emaravirus & $37.26 \%$ & $26.55 \%$ & $30.82 \%$ & $23.10 \%$ & - & - \\
\hline & & QAB47307.1 & QAB47308.1 & QAB47309.1 & QAB47310.1 & & \\
\hline \multirow[t]{2}{*}{14} & Raspberry leaf blotch emaravirus & $36.87 \%$ & $26.98 \%$ & $28.57 \%$ & $24.08 \%$ & $31.91 \%$ & - \\
\hline & & YP_009237274.1 & YP_009237265.1 & YP_009237266.1 & YP_009237267.1 & YP_009237268.1 & \\
\hline \multirow[t]{2}{*}{15} & Palo verde broom virus & $35.24 \%$ & $26.42 \%$ & $24.42 \%$ & $27.00 \%$ & - & - \\
\hline & & AWH90165.1 & AWH 90170.1 & AWH90176.1 & AWH90182.1 & & \\
\hline \multirow[t]{2}{*}{16} & Jujube yellow mottle-associated virus & $37.60 \%$ & $28.39 \%$ & $28.23 \%$ & $24.53 \%$ & - & - \\
\hline & & QDM38999.1 & QDM39000.1 & QDM39001.1 & QDM39002.1 & & \\
\hline
\end{tabular}




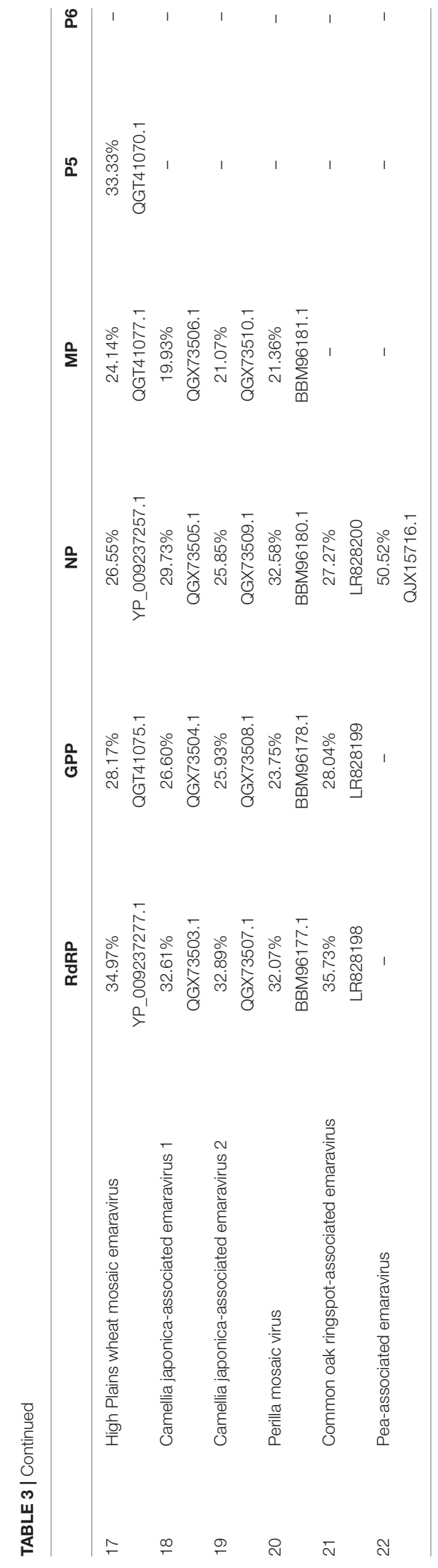

homology (supported by $E$-values $<0.01$ ) with the corresponding protein detected from eight emaraviruses (30-43\% aa identity). This putative protein shares highest identity with the $\mathrm{P} 5$ protein of rose rosette virus (Accession number: QIB98219. 1; aa identity: $44.8 \%$ ), a protein of unknown function. The rest of the emaraviruses do not have a homologous protein or such has not been identified yet.

Finally, the sixth ORF, encoded on RNA6 (nt positions 766 71 ), produces a 231 aa-long protein with $35-45 \%$ aa identity with that of other emaraviruses. The highest aa identity is with the P6 protein from Actinidia emaravirus 2 (Accession number: QEE82891.1; aa identity: 44.2\%). The novel virus is found to have a homologous protein to the one encoded by RNA6 segment of only eight from the already known emaraviruses.

Elbeaino et al. (2018) in the 10th report of the International Committee on Taxonomy of Viruses regarding the taxonomy of Fimoviridae describe that the virus genome of the family members comprises from four negative-sense ssRNA segments [like the type species European mountain ash ringspot-associated emaravirus (EMARaV) from the host European mountain ash] to eight RNA segments [High Plains wheat mosaic virus (Tatineni et al., 2014)]. Later, two novel emaravirus with five RNA segments were identified; lilac chlorotic ringspot-associated virus from lilac leaves with yellow mottle symptoms in China (Wang et al., 2020) and ti ringspot-associated virus from the ti plant (Cordyline fruticosa) in Hawaii (Olmedo-Velarde et al., 2019). Six genomic RNA segments were identified in jujube yellow mottle-associated virus causing the same named disease in jujube (Ziziphus jujuba) in China (Yang et al., 2019). Very recently, a novel emaravirus in Shiso named Perilla mosaic virus (PerMV) was found to consist of 10 RNA segments, each encoding a single protein in the negativesense orientation (Kubota et al., 2020). In the case of the maple virus two independent NGS samples from the same maple tree detected the same number of genome segments. Additionally, for the Acer+ (2015) sample, the cDNA library was prepared using a primer targeting the conserved genome terminal region, known to be shared among emaraviruses genome segments. A screen for further genome segments containing these terminal regions did not reveal further sequences and we therefore consider that it is unlikely to have missed additional RNA segments of the viral genome. Concluding, we suggest that the segments RNA1-RNA6 represent the complete genome of the novel virus constituting a new member of the family Fimoviridae.

\section{Phylogenetic Analysis of the Novel Emaravirus}

Phylogenetic relationships between the maple virus and the sequences of 21 emaraviruses known to date were estimated, based on amino acid sequences comparisons. Irrespective of the RNA segment investigated, the maple viral agent clusters consistently in "subgroup a" (according to Elbeaino et al., 2018), together with - among others - rose rosette virus, fig mosaic virus, the novel aspen mosaic-associated virus, the two pigeon pea sterility mosaic emaraviruses and Actinidia emaravirus 2. The phylogenetic analysis performed here confirms the overall structure within the genus Emaravirus described by von Bargen 


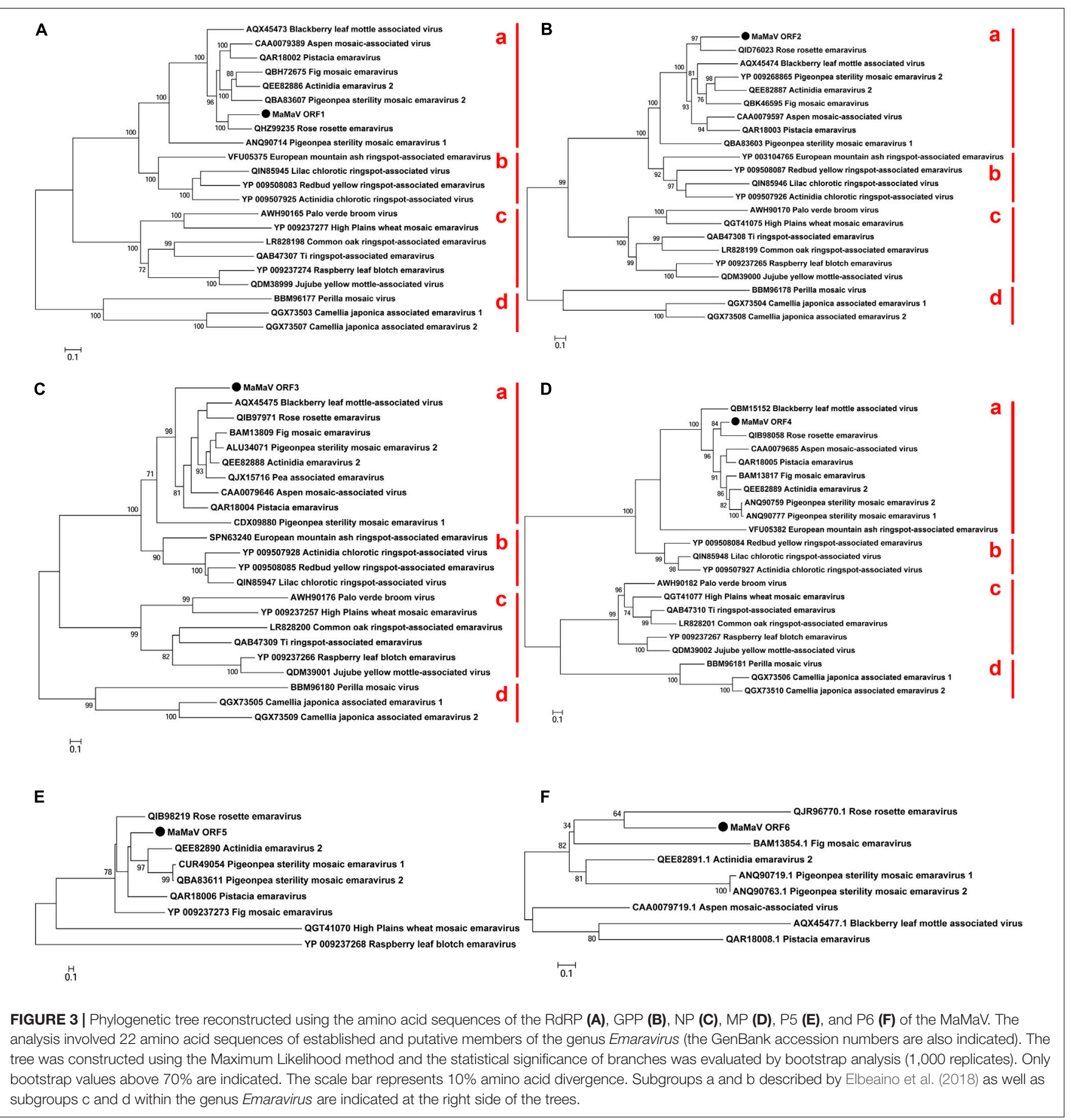

et al. (2020a) and enriches the tree with seven additional emaraviruses. Figures 3A-D shows representative ML trees obtained using the putative RdRP, the GPP, the NP and the MP encoded by the genome segments RNA1, RNA2, RNA3, and RNA4, respectively. The maple emaravirus proteins $\mathrm{P} 5$ and P6 are homologous to those of eight different emaraviruses (Figures 3E,F). All predicted proteins cluster together with the respective ones from rose rosette virus. The only exception is the NP protein, which still clusters with the "subgroup a," but with no close relation to any of its members. Additionally, a fourth subgroup is constructed ("subgroup d") based on the phylogenetic relationships inferred from ORF1 - ORF4 amino acid sequences, which consists of three recently discovered viruses, the perilla mosaic virus and the camellia japonicaassociated emaraviruses 1 and 2 .

The novel aa sequences, as it is shown from the phylogenetic analysis, are clearly genetically differentiated from all encoded proteins identified to date and cluster together with the ones from the "subgroup a." This result was already drawn by the taxonomic analysis with MEGAN, where the novel virus was shown to be 
close related to the "subgroup a" member pigeon pea sterility mosaic emaravirus (PPSMV) (without differentiation between PPSMV-1 and PPSMV-2). At the same time, all predicted proteins of the maple emaravirus exhibit significant aa identities only with the ones from other emaraviruses. Taken together, these results demonstrate that the virus identified represents a new species in the genus Emaravirus and it is, therefore, tentatively named maple mottle-associated virus (MaMaV).

\section{Validation of the RNA-Seq Results and Association of Virus Presence With Symptom Appearance}

From the 32 maple trees tested by specific RT-PCR, MaMaV was only detected in the symptomatic ones and all six RNAs were generally simultaneously detected (Supplementary Table 1). For a few samples, one of the six RNA segments failed to be amplified [i.e., RNA2 in sample E54934; RNA1 (using primers RNA1bF/R) in samples E54936 and E54942 (although primers RNA1aF/R did produce amplicons with these samples); RNA5 in sample E54946]. Because these cases were rare and all other RNA segments in those samples were successfully amplified, we suggest the negative results were due to the low concentration of respective RNA segments beyond detection limit of the RTPCR assay. Non-symptomatic samples were consistently negative for all MaMaV segments. These results suggest that the 26 positive-tested symptomatic maples were MaMaV-infected and that MaMaV could be the virus responsible for the identified virus-like symptoms.

It should be, however, underlined that the tested trees showed a variability of symptoms, where mottle was mainly observed, but other -weaker or stronger- symptoms were also exhibited. Although mottle was the main and common symptom exhibited in the majority of infected trees, occasionally other virus-like symptoms, like chlorotic ringspots, line pattern or flecking and in some rare cases also leaf deformations were observed. More concretely, apart from mottle, in 2015 also flecking was recorded, while in 2016 chlorotic ringspots and line pattern were observed, although in both years samples were collected at the same time (1st of July; see Supplementary Table 1).

\section{Preliminary Results on Genetic Variability of Three RNA Segments}

The evolutionary divergence between variants from different trees was estimated for three RNA segments. In these RNA segments low genetic diversity was estimated; maximal divergence among RT-PCR products amplified with primer-pairs $\mathrm{RNA} 1 \mathrm{aF} / \mathrm{R}$ and $\mathrm{RNA} 1 \mathrm{bF} / \mathrm{R}$ was $2 \%$ and $1.1 \%$, respectively. Sequences were identical in two and in 13 of the pairwise comparisons for the RNA1aF/R and RNA1bF/R RT-PCR products, respectively. However, all sequences differed from the corresponding variant generated from the original sequence from Acer + (2014) by $0.3-1.6 \%$ and by $0.4-1.1 \%$ in the cases of the RT-PCR products amplified by primer-pair RNA1aF/R and RNA1bF/R, respectively (Supplementary Table 2). Regarding variability among RT-PCR products for the RNA3 and among RT-PCR products from the RNA4 segment, no genetic diversity was shown among the respective sequences and all were identical with the corresponding segment from the original sample Acer+ (2014).

Based on these results, evidence is provided that the diversity in the local Berlin-Grunewald MaMaV population is generally low and that different level of genetic diversity may characterize its different genome segments.

\section{DISCUSSION}

The six newly identified RNA segments are attributed to a novel Emaravirus species based on the following: (a) The multipartite genome is composed of six single-stranded RNA molecules; (b) All six RNAs share a fully conserved stretch of $13 \mathrm{nt}$ at their $5^{\prime}$ and $3^{\prime}$ termini; (c) Each segment of the genome encodes a single protein, which shows sequence identity with homologous proteins of other emaraviruses; (d) In all phylogenetic trees generated with amino acid sequences, MaMaV is only distantly related phylogenetically to the emaraviruses currently represented in the GenBank fulfilling the current species demarcation criteria of emaraviruses to show more than $25 \%$ aa divergence of RNA1-RNA3 encoded proteins (Elbeaino et al., 2018). To our knowledge, for first time an emaravirus is described from maple and is fully genetically characterized.

The NGS method applied not only led to the discovery and genetic characterization of the novel emaravirus; it unraveled at the same time the maple virome, in terms of identifying the exhaustive collection of nucleic acid sequences deriving from viral agents. The maple virome of the symptomatic tree tested is found to be very simple, as it includes a single variant from a single virus. The lack of virome complexity is rather surprising, when we consider obtained NGS results from other wild as well as cultivated woody hosts. A complex virome was revealed in birch, where up to five virus variants were identified in the transcriptome of individual trees (Rumbou et al., 2020). In birch, it has been demonstrated that not only multiple viral species but also diverse variants of the same virus may accumulate in single trees (Rumbou et al., 2016, 2020). Similarly, in single peach trees multi-viral infection of up to six viruses and viroids was detected (Jo et al., 2018). A multiplicity of viral infections was also shown in metagenome samples from single plum trees (Jo et al., 2020). A possible explanation for the single viral infection in the maple tree could be the age of the tree; it was very young (approx. 3 years-old) when sampled, thus it was exposed for only a short time to viral pathogens.

The novel virus was only present in the tested symptomatic maple trees in Berlin, while it was not detected in nonsymptomatic trees. This suggests that $\mathrm{MaMaV}$ presence is associated with the leaf symptoms identified in maples. Maple seedlings scions from Berlin-Grunewald were grafted to nonsymptomatic 2-year old maple rootstocks in March 2017 (data not shown). In 2018 the grafted seedlings exhibited mottle, while MaMaV could be detected in the scions by RT-PCR in 2019 and in 2020. Detection of MaMaV in rootstocks was not yet possible, as either the grafted seedlings did not develop shoots from rootstocks, or non-symptomatic shoots from rootstocks 
were not tested. Although the main observed symptom was mottle, other -weaker or stronger- symptoms were also exhibited. Whether MaMaV is the only causal agent for the different kind of symptoms or whether other viruses are also involved in the symptomatology needs to be further investigated. Further efforts are needed to satisfy Koch's postulates and firmly establish its causal role.

In maple trees, virus-like symptoms other than mottle have been observed and reported earlier not only in Germany (Bandte et al., 2008; Büttner et al., 2013), but also in Romania (Ploiaie and Macovei, 1968), Hungary (Szirmai, 1972), Turkey (Erdiller, 1986), North America (Brierley, 1944), United Kingdom (Cooper, 1979). Symptom descriptions such as "mosaic," "chlorotic mottle," "yellow-mottle," "ring-mottle," "mosaic mottling with chlorotic spots" were used by earlier researchers. Whether the newly identified virus might be associated with the symptoms described in these earlier studies remains to be determined, given in particular that electrondense structures known as double-membrane-bound bodies with diameters differing within the range of $80-200 \mathrm{~nm}$ and typical of emaraviruses (Mielke-Ehret and Mühlbach, 2012) have never been reported in earlier electron microscopy samples from symptomatic maples, while more typical plant virus particles sometimes have. Furthermore, infection of maples by tobamoviruses reported by Führling and Büttner (1998) could not be confirmed by the present study. In that case, we suggest either that the samples observed by EM were contaminated during sample processing or that indeed tobamoviruses may also affect maples. It remains to be confirmed by future NGS analyses whether other viral agents may be present in symptomatic maples.

From the discovery of the first viral agent in maple thanks to the development of NGS's tools to its full biological characterization there is a long way to go (Massart et al., 2017). To investigate its potential for emergence, possible vectors and mode(s) of dispersal need to be determined. Several members of the genus Emaravirus are known to be transmitted by eriophyid mites (Acari: Eriophyidae) (Mielke-Ehret and Mühlbach, 2012; Hassan et al., 2017; Elbeaino et al., 2018). In the present study, in several of the sampled trees damages from gall mites (Aceria macrophylla, Eriophyes psilomerus) as well as from leafhoppers were found. The gall mites can be considered as putative vectors, but the hypothesis that they may be involved in the emaravirus transmission needs to be studied. Regarding MaMaV's impact on infected trees, we assume that the mottle symptoms exhibited in infected leaves may lead to reduced photosynthetic capacity and, consequently, to trees' health deterioration. Based on the available diagnostic RT-PCR assays designed in the frame of the present study, the investigation of the agents' distribution and its impact on the trees health can be estimated.

During the last decade a significant number of novel DNA and RNA viruses (Villamor et al., 2019) and viroids (Hadidi, 2019) have been uncovered in herbaceous as well as in woody hosts by applying a wide range of NGS methods for virus detection and discovery (Hadidi et al., 2016; Olmos et al., 2018; Villamor et al., 2019). In comparison to other viruses, emaraviruses were until recently overlooked, not only when applying conventional methods, but also by metagenomic studies (Bejerman et al., 2020). The application of NGS resulted in the discovery of 13 emaraviruses during the last 5 years (Bejerman et al., 2020). By employing NGS methodologies a significant presence of emaraviruses in forests has been revealed. In the last 3 years four emaraviruses have been discovered in six forest or urban tree species; aspen mosaic-associated virus (AsMaV) in Populus tremula (von Bargen et al., 2020a), European mountain ash ringspot-associated virus (EMARaV) in Sorbus intermedia (von Bargen et al., 2019), Karpatiosorbus $\times$ hybrid (von Bargen et al., 2020b), and Amelanchier sp. (von Bargen et al., 2018), common oak ringspot-associated virus (CORaV) in Quercus robur (Bandte et al., 2020), and maple mottle-associated virus (MaMaV) in Acer pseudoplatanus. Based on existing knowledge on viral disease of fruit trees (Hadidi et al., 2011) we suggest that viral agents might be a considerable stress factor for forests trees, they may predispose affected trees to other more harmful stress factors and, as a consequence, lead to deterioration of forests and other natural ecosystems (Büttner et al., 2013, 2015). Additional efforts in the field of forest virology are needed to provide data on the magnitude of the tree damage due to viral infections and to prevent future viral outbreaks.

\section{DATA AVAILABILITY STATEMENT}

The datasets presented in this study can be found in online repositories. The names of the repository/repositories and accession number(s) can be found below: https://www.ncbi.nlm. nih.gov/, MT879190-MT879195.

\section{AUTHOR CONTRIBUTIONS}

AR and CB: conceptualization. AR and TC: data curation, formal analysis, and software. CB: funding acquisition and project administration. AR, TC, and SB: investigation and validation. AR and SB: methodology and visualization. AR: writing - original draft. TC, CB, and SB: Writing - review and editing. All authors contributed to the article and approved the submitted version.

\section{FUNDING}

This work was supported by the German Research Foundation (DFG) (project BU890/27-1).

\section{ACKNOWLEDGMENTS}

This work is partly accomplished in the frame of the COST Action FA1407-DIVAS (Deep Investigation of Virus Associated Sequences) - "Application of next-generation sequencing for the study and diagnosis of plant viral diseases in agriculture." We deeply thank all colleagues from this COST action for their support to acquire the results - directly or indirectly and for the fruitful and open scientific exchange. We also acknowledge support by the German Research Foundation 
(DFG) and the Open Access Publication Fund of HumboldtUniversität zu Berlin.

\section{SUPPLEMENTARY MATERIAL}

The Supplementary Material for this article can be found online at: https://www.frontiersin.org/articles/10.3389/fmicb. 2020.621179/full\#supplementary-material

\section{REFERENCES}

Atanasoff, D. (1935). Old and new virus diseases of trees and shrubs. Phytopathol. Z. 8, 197-223.

Bandte, M., Hamacher, J., and Büttner, C. (2008). "Maple tree (Acer sp.) infected by viruses and phytoplasma," in Jahrbuch der Baumpflege: ThalackerMedien, eds H. D. Dujesiefken and P. Kockerbeck (Braunschweig: Deutsche Baumpflegetage), 208-212.

Bandte, M., Rehanek, M., Leder, B., von Bargen, S., and Buettner, C. (2020). Identification of an emaravirus in a common Oak (Quercus robur L.) Conservation seed orchard in germany: implications for Oak health. Forests 11:1174. doi: 10.3390/f11111174

Bejerman, N., Debat, H., and Dietzgen, R. G. (2020). The plant negative-sense RNA virosphere: virus discovery through new eyes. Front. Microbiol. 11:588427. doi: 10.3389/fmicb.2020.588427

Binggeli, P. (1993). Sycamore lore. Plant Lore Notes News 29, 131-133.

Boom, R., Sol, C. J. A., Salians, M. M. M., Jansen, C. L., Wertheim-van Dillen, P. M. E., and van der Noordaa, J. (1990). Rapid and simple method for puri cation of nucleic acids. J. Clin. Microbiol. 28, 495-503.

Brglez, A., Piškur, B., and Ogris, N. (2020). Eutypella parasitica and other frequently isolated fungi in wood of dead branches of young sycamore maple (Acer pseudoplatanus) in slovenia. Forests 11:467. doi: 10.3390/f11040467

Brierley, P. (1944). Viruses described primarily on ornamental or miscellaneous hosts. Pl. Dis. Reptr. 150, 410-482. (mimeographed).

Büttner, C., von Bargen, S., and Bandte, M. (2015). "Chapter 13: phytopathogenic viruses," in Principles of Plant Microbe Interactions: Role of Microbes in Sustainable Agriculture, ed. Lugtenberg (Heidelberg: Springer), 115-122. doi: 10.1007/978-3-319-08575-3_13

Büttner, C., von Bargen, S., Bandte, M., and Muehlbach, H. P. (2013). "Forests diseases caused by viruses," in Infectious Forest Diseases, eds P. Gonthier and G. Nicolotti (CABI), 50-75.

Cooper, J. I. (1979). Virus Disease of Trees and Shrubs. Oxford: Institute of Terrestrial Ecology, Natural Environment Research Council.

Di Bello, P. L., and Tzanetakis, I. E. (2013). Rose rosette virus is the causal agent of rose rosette disease. Phytopathology 103:S1.

Elbeaino, T., Digiaro, M., Mielke-Ehret, N., Muehlbach, H. P., and Martelli, G. P. (2018). ICTV report consortium, ICTV virus taxonomy profile: fimoviridae. J. Gen. Virol. 99, 1478-1479. doi: 10.1099/jgv.0.001143

Erdiller, G. (1986). Acer virus diseases in Turkey. J. Turkish Phytopathol. 15, 46-59.

Führling, M., and Büttner, C. (1998). Nachweis von Tobamo-Viren in Bergahorn (Acer pseudoplatanus L.) mit Scheckung und Blattdeformation. Forstw. Cbl. 117, 92-97. doi: 10.1007/bf02832962

Gibbs, D., and Chen, Y. (2009). The Red List of Maples. Archived 2019-05-28 at theWayback Machine. Richmond: Botanic Gardens Conservation International (BGCI).

Hadidi, A. (2019). Next-generation sequencing and CRISPR/Cas13 editing in viroid research and molecular diagnostics. Viruses 11:120. doi: 10.3390/ v11020120

Hadidi, A., Barba, M., Candresse, T., and Jelkmann, W. (2011). Virus and VirusLike Diseases of Pome and Stone Fruits. St. Paul, MN: APS Press.

Hadidi, A., Flores, R., Candresse, T., and Barba, M. (2016). Next-generation sequencing and genome editing in plant virology. Front. Microbiol. 7:1325.

Hassan, M., Di Bello, P. L., Keller, K. E., Martin, R. R., Sabanadzovic, S., and Tzanetakis, I. E. (2017). A new, widespread emaravirus discovered in blackberry. Virus Res. 235, 1-5. doi: 10.1016/j.virusres.2017.04.006
Supplementary Table 1 | Samples used for RT-PCR validation and genetic divergence analysis. Sample label, collection date, tree location, symptoms exhibited, damage caused by pests and the RT-PCR results (+/-) for each of the RT-PCR assays applied with seven different primer-pairs in 6 RNA segments of the novel emaravirus are shown.

Supplementary Table 2 | Estimates of evolutionary divergence among RT-PCR products from 10 maple trees and the original Acer+ (2014). (A) RT-PCR products amplified with primer-pair RNA1aF/R. (B) RT-PCR products amplified with primer-pair RNAbF/R.

Huson, D. H., Beier, S., Flade, I., Górska, A., El-Hadidi, M., Mitra, S., et al. (2016). MEGAN community edition - interactive exploration and analysis of large-scale microbiome sequencing data. PLoS Comput. Biol. 12:e1004957. doi: 10.1371/ journal.pcbi.1004957

Jo, Y., Choi, H., Lian, S., Cho, J. K., Chu, H., and Cho, W. K. (2020). Identification of viruses infecting six plum cultivars in Korea by RNA-sequencing. PeerJ 8:e9588. doi: 10.7717/peerj.9588

Jo, Y., Lian, S., Chu, H., Cho, J. K., Yoo, S.-H., Choi, H., et al. (2018). Peach RNA viromes in six different peach cultivars. Sci. Rep. 8:1844. doi: 10.1038/s41598018-20256-w

Kaminska, M., and Suwa, H. (2006). First report of a decline of ash leaf maple (Acer negundo) in Poland, associated with Candidatus Phytoplasma asteris. Plant Pathol. 55:293. doi: 10.1111/j.1365-3059.2005.01304.x

Kubota, K., Usugi, T., Tomitaka, Y., Shimomoto, Y., Takeuchi, S., Kadono, F., et al. (2020). Perilla mosaic virus is a highly divergent emaravirus transmitted by Shevtchenkella sp. (Acari: Eriophyidae). Phytopathology 7, 1352-1361. doi: 10.1094/PHYTO-01-20-0013-R

Lana, A. E., Thomas, O. T., and Peterson, J. E. (1980). A virus isolated from sugar maple. Phytopathol. Z 97, 214-218. doi: 10.1111/j.1439-0434.1980.tb03689.x

Larsson, A. (2015). AliView: a fast and lightweight alignment viewer and editor for large datasets. Bioinformatics 30, 3276-3278. doi: 10.1093/bioinformatics/ btu531

Lefebvre, M., Theil, S., Ma, Y., and Candresse, T. (2019). The VirAnnot pipeline: a resource for automated viral diversity estimation and operational taxonomy units (OTU) assignation for virome sequencing data. Phytobiom. J. 3, 256-259. doi: 10.1094/PBIOMES-07-19-0037-A

Li, Z.-N., Zhang, L., Zhao, L., and Wu, Y.-F. (2012). A new phytoplasma associated with witches-broom on Japanese maple in China. For. Path. 42, 371-376. doi: 10.1111/j.1439-0329.2012.00769.x

Massart, S., Candresse, T., Gil, J., Lacomme, C., Predajna, L., Ravnikar, M., et al. (2017). A framework for the evaluation of biosecurity, commercial, regulatory and scientific impacts of plant viruses and viroids identified by NGS technologies. Front. Microbiol. 8:45. doi: 10.3389/fmicb.2017.00045

Mielke-Ehret, N., and Mühlbach, H.-P. (2012). Emaravirus: a novel genus of multipartite, negative strand RNA plant viruses. Viruses 4, 1515-1536. doi: $10.3390 / \mathrm{v} 4091515$

Mihara, T., Nishimura, Y., Shimizu, Y., Nishiyama, H., Yoshikawa, G., Uehara, H., et al. (2016). Linking virus genomes with host taxonomy. Viruses 8:66. doi: $10.3390 / v 8030066$

Olmedo-Velarde, A., Park, A. C., Sugano, J., Uchida, J. Y., Kawate, M., Borth, W. B., et al. (2019). Characterization of ti ringspot-associated virus, a novel emaravirus associated with an emerging ringspot disease of cordyline fruticosa. Plant Dis. 103:9. doi: 10.1094/PDIS-09-18-1513-RE

Olmos, A., Boonham, N., Candresse, T., Gentit, P., Giovani, B., Kutnjak, D., et al. (2018). High-throughput sequencing technologies for plant pest diagnosis: challenges and opportunities. EPPO Bull. 48, 219-224. doi: 10.1111/epp. 12472

Ploiaie, P. G., and Macovei, A. (1968). New plant virosis recorded in Roumania. Revue. Roum. Biol. (Ser. Bot.) 13, 269-274.

Rumbou, A., Candresse, T., Marais, A., Svanella-Dumas, L., Landgraf, M., von Bargen, S., et al. (2020). Unravelling the virome in birch: RNA-Seq reveals a complex of known and novel viruses. PLoS One 15:e221834. doi: 10.1371/ journal.pone.0221834

Rumbou, A., Candresse, T., Marais, A., Theil, S., Langer, J., Jalkanen, R., et al. (2018). A novel badnavirus discovered from Betula sp. affected by birch leaf-roll disease. PLoS One 13:e0193888. doi: 10.1371/journal.pone.0193888 
Rumbou, A., von Bargen, S., Demiral, R., Langer, J., Rott, M., Jalkanen, R., et al. (2016). High genetic diversity at the inter-/intra-host level of Cherry leaf roll virus population associated with the birch leaf-roll disease in Fennoscandia. Scand. J. For. Res. 31, 546-560. doi: 10.1080/02827581.2016.1165283

Subikova, V. (1973). The mechanical transmission of Euonymus mosaic virus, maple leaf perforation by leaf extracts or leaf nucleic acid to herbaceous plants. Biologia Plant. 15, 166-170. doi: 10.1007/bf02922389

Szirmai, J. (1972). An Acer virus disease in maple trees planted in Avenues. Acta Phytopathol. Acad. Sci. Hung. 7, 197-207.

Tamura, K., Nei, M., and Kumar, S. (2004). Prospects for inferring very large phylogenies by using the neighbor-joining method. Proc. Natl. Acad. Sci. U.S.A. 101, 11030-11035. doi: 10.1073/pnas.0404206101

Tamura, K., Stecher, G., Peterson, D., Filipski, A., and Kumar, S. (2013). MEGA6: molecular evolutionary genetics analysis version 6.0. Mol. Biol. Evol. 30, 27252729. doi: $10.1093 / \mathrm{molbev} / \mathrm{mst} 197$

Tatineni, S., McMechan, A. J., Wosula, E. N., Wegulo, S. N., Graybosch, R. A., French, R., et al. (2014). An eriophyid mite-transmitted plant virus contains eight genomic RNA segments with unusual heterogeneity in the nucleocapsid protein. J. Virol. 88, 11834-11845. doi: 10.1128/jvi.01901-14

Villamor, D. E. V., Ho, T., Al Rwahnih, M., Martin, R. R., and Tzanetakis, I. E. (2019). High throughput sequencing for plant virus detection and discovery. Phytopathology 109, 716-725. doi: 10.1094/phyto-07-18-0257-rvw

von Bargen, S., Al Kubrusli, R., Gaskin, T., Fürl, S., Hüttner, F., Blystad, D.-R., et al. (2020a). Characterisation of a novel Emaravirus identified in mosaicdiseased Eurasian aspen (Populus tremula). Ann. Appl. Biol. 176, 210-222. doi: 10.1111/aab.12576

von Bargen, S., Bandte, M., Al Kubrusli, R., Jalkanen, R., and Büttner, C. (2020b). First report of European mountain ash ringspot-associated virus in Karpatiosorbus $\times$ hybrida in Finland. New Dis. Rep. 42:1.

von Bargen, S., Dieckmann, H.-L., Candresse, T., Mühlbach, H.-P., Roßbach, J., and Büttner, C. (2019). Determination of the complete genome sequence of European mountain ash ringspot-associated emaravirus from Sorbus intermedia reveals two additional genome segments. Arch Virol. 164, 19371941. doi: 10.1007/s00705-019-04275-0

von Bargen, S., Tischendorf, M., and Büttner, C. (2018). First report of European mountain ash ringspot-associated virus in serviceberry (Amelanchier spp.) in Germany. New Dis. Rep. 37, 19-19. doi: 10.5197/j.2044-0588.2018. 037.019

Wang, Y., Song, Y., Cao, M., Cheng, Q., Wu, J., and Hu, T. (2020). Identification of a novel emaravirus infecting lilac through next-generation sequencing. J. Integr. Agricult. 19, 2064-2071. doi: 10.1016/S2095-3119(19)628066

Wulf, A., and Kehr, R. (2009). "Diseases, disorders and pests of selected valuable broadleaved tree species," in Valuable Broadleaved Forests in Europe, eds H. Spiecker, S. Hein, K. Makkonen-Spiecker, and M. Thies (Leiden: Brill), 61-84.

Yang, C., Zhang, S., Han, T., Fu, J., Di Serio, F., and Cao, M. (2019). Identification and characterization of a novel emaravirus associated with jujube (Ziziphus jujuba Mill.) yellow mottle disease. Front. Microbiol. 10:1417. doi: 10.3389/ fmicb.2019.01417

Zhang, Y. Z., Shi, M., and Holmes, E. C. (2018). Using metagenomics to characterize an expanding virosphere. Cell 172, 1168-1172. doi: 10.1016/j.cell. 2018.02.043

Conflict of Interest: The authors declare that the research was conducted in the absence of any commercial or financial relationships that could be construed as a potential conflict of interest.

Copyright (c) 2021 Rumbou, Candresse, von Bargen and Büttner. This is an openaccess article distributed under the terms of the Creative Commons Attribution License (CC BY). The use, distribution or reproduction in other forums is permitted, provided the original author(s) and the copyright owner(s) are credited and that the original publication in this journal is cited, in accordance with accepted academic practice. No use, distribution or reproduction is permitted which does not comply with these terms. 